\title{
Stability Analysis of VSC MTDC Grids Connected to Multi-machine AC Systems
}

\author{
Nilanjan Ray Chaudhuri, Member, IEEE, Rajat Majumder, Member, IEEE, Balarko Chaudhuri, Member, IEEE, \\ and Jiuping Pan, Senior Member, IEEE
}

\begin{abstract}
Interaction between multi-machine AC systems and a multi-terminal DC (MTDC) grid and the impact on the overall stability of the combined AC-MTDC system is studied in this paper. A generic modeling framework for VSC-based MTDC grids which is compatible with standard multi-machine AC system models is developed to carry out modal analysis and transient simulation. A general asymmetric bipole converter configuration comprising positive and negative pole converters and DC cable network with positive, negative and metallic return circuit is considered to enable different types of faults and DC side unbalance studies. Detailed dynamic representation of the DC cables with distributed pi-section models is used along with the averaged model and decoupled control for the converter stations. Averaged model in Matlab/SIMULINK is validated against the detailed switched model in EMTDC/PSCAD by comparing the responses following small and large disturbances (e.g. faults on the DC side). Modal analysis is performed to identify the nature and root cause of the dynamic responses. Interaction between a multi-machine AC system and an MTDC grid is examined following faults on both $\mathrm{AC}$ and DC sides and outage of converters. It is shown that the cause of instability in certain cases could only be attributed to the DC side state variables. An averaged model of the converter along with the DC cable network is shown to be essential to analyze the stability and dynamics of combined AC-MTDC grids.
\end{abstract}

Index Terms-Multi-terminal DC (MTDC), Voltage source converter (VSC), Stability, Modal analysis, Participation factor

\section{INTRODUCTION}

I $\mathrm{T}$ is envisaged that a sub-sea multi-terminal DC grid based on voltage source converter (VSC) technology would be built around the North sea to tap the rich wind resource of the region and also interconnect the UK and Nordic pool with continental Europe [1]. From network operators' point of view, possibility of an enormous loss of in-feed (tens of gigawatts) due to a single-point failure in such VSC based MTDC grid is one of the major concerns. Following DC side faults, isolating only the faulty component (a converter or a cable) of the MTDC grid is a challenge. Besides protection and DC breaker development issues there are primary control problems like autonomous sharing of power imbalance among the converters following a converter or cable outage. Moreover, the MTDC grid could be required to provide AC system support like frequency control. To study these issues, interaction between multi-machine AC systems and a multi-terminal DC (MTDC)

Support from EPSRC,UK under grant EESC P11121 is acknowledged.

N.R. Chaudhuri and B. Chaudhuri are with Imperial College London, London, UK (e-mail: n.chaudhuri@imperial.ac.uk,b.chaudhuri@imperial.ac.uk).

R. Majumder and J. Pan are with the ABB Corporate Research, Raleigh, NC, USA (e-mail: rajat.majumder@us.abb.com, jiuping.pan@us.abb.com). grid along with the impact on the overall stability of the combined AC-MTDC system needs investigation and is the subject matter of this paper.

A lot of research attention has been focused on MTDC grids based on the current source converter (CSC) technology. Modeling of such systems and representation in stability program are well reported [2], [3]. However, VSC-based MTDC has received relatively less attention until recent past when modeling [4], [5], control strategies [6], [7], [8] and protection [9] were studied. There are certain limitations in the studies of the VSC based MTDC grids reported in literature:

- Till now stability studies involving such grids is only based on time-domain simulations. Modal (eigen values, mode shapes, participation factor etc.) analysis - which is essential to characterize the system dynamic responses has not been presented.

- Interaction between the MTDC grid and surrounding multi-machine AC system is yet to be reported.

- No analysis considering a fault on the DC grid followed by $\mathrm{DC}$ cable outage and converter outage is presented in this context.

The focus of this paper is to fill in these gaps.

In this work an asymmetric bipole ${ }^{1}$ MTDC model with the provision of metallic return network is considered. The modeling framework is generic enough to accommodate a detailed pi section approximation of DC side cables and simulate different types of DC cable faults followed by outages. The proposed averaged model in Matlab/SIMULINK is validated against a detailed switched model in EMTDC/PSCAD software enabling easy integration of the MTDC grid with the multi-machine AC system models for stability studies. This provides a platform for studying possible interaction amongst the MTDC grid primary controls (e.g. the autonomous power sharing etc.) and the AC systems.

The contributions of this paper are:

1) Modeling of a general asymmetric bi-polar MTDC grid for stability analysis considering DC-side faults, cable outages, converter outage and unbalanced DC-side operation.

2) Validating the averaged model for small-signal analysis in Matlab/SIMULINK against a detailed switched model in EMTDC/PSCAD.

3) Modal analysis of MTDC grid to characterize different modes using participation factors.

${ }^{1}$ unlike symmetric bipole, an asymmetric bipole has the metallic return circuit to carry the current due to unbalance 
4) Analysis of interaction between $\mathrm{AC}$ and MTDC grids following faults on both $\mathrm{AC}$ and $\mathrm{DC}$ sides and outage of converters.

\section{Modeling}

\section{A. Converter Modeling}

The single line diagram of a converter and its controls is shown in Fig. 1. From Fig. 1 the KVL equation of AC side

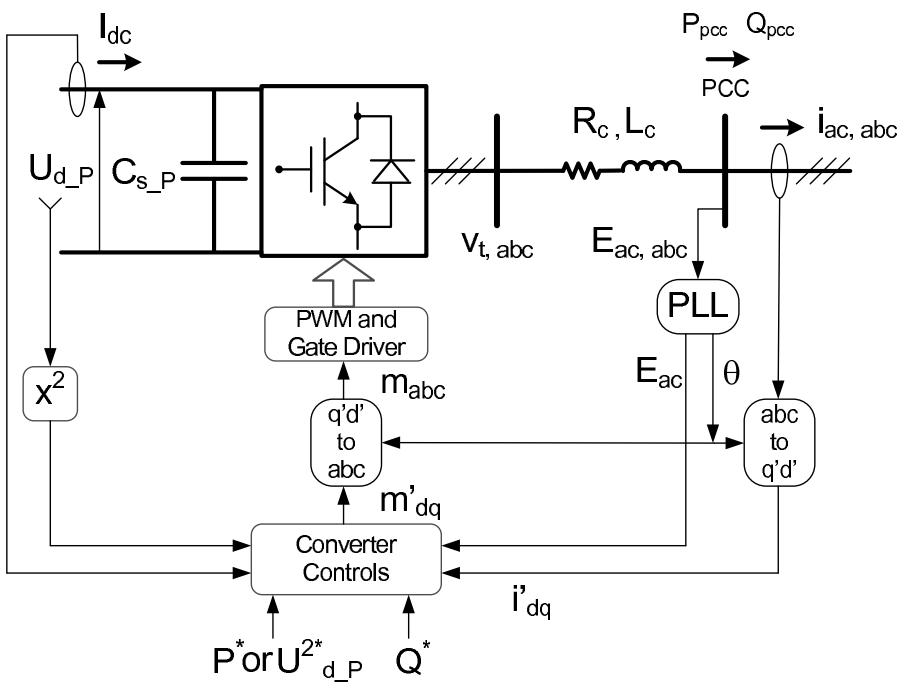

Fig. 1. Single line diagram of a converter and controls

of the converter in abc frame can be written as:

$$
v_{t, a b c}-E_{a c, a b c}=R_{c} i_{a c, a b c}+L_{c} \frac{d i_{a c, a b c}}{d t}
$$

where, $R_{c}, L_{c}$ are the aggregated resistance and inductance of the converter transformer and phase reactors. This equation can be expressed in a space-phasor (or space-vector) form [10] as:

$$
\vec{v}_{t}-\vec{E}_{a c}=R_{c} \vec{i}_{a c}+L_{c} \frac{d \vec{i}_{a c}}{d t}
$$

A phase-locked loop (PLL) ensures that the $d^{\prime}$-axis of a synchronously rotating reference frame $q^{\prime}-d^{\prime}$ is locked with the voltage $\vec{E}_{a c}$ (Fig. 1) to ensure decoupled control of the active and reactive power. Fig. 1 also shows the feedback and measurable disturbance parameters (feed-forwards) used by the controller, which in turn generates the modulation signal $m_{q d}^{\prime}$. The modulation signal $m_{q d}^{\prime}$ is then translated back to $a b c$ frame with the help of the reference angle $\theta$ produced by the PLL to generate the sinusoidal pulse-width modulation (SPWM) switching signals.

For stability studies, it is a common practice to model the power system in $d-q$ frame of reference with the $d$ axis leading the $q$-axis following the IEEE convention [11] as shown in Fig. 2(b). The converters were represented by their averaged model [12] in Matlab/SIMULINK. The positive pole converter model is shown in Fig. 2(a) in the same reference frame as the controllers (i.e. $q^{\prime}-d^{\prime}$ frame). All notations in the modified reference frame are henceforth denoted with a prime. Therefore, the AC system variables (say, $\vec{E}_{a c}$ ) needs to be transformed to $q^{\prime}-d^{\prime}$ frame and the converter variables

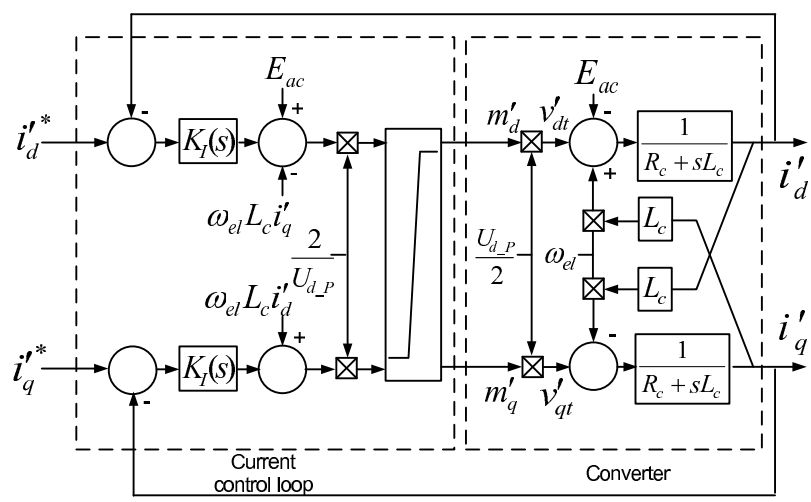

(a)

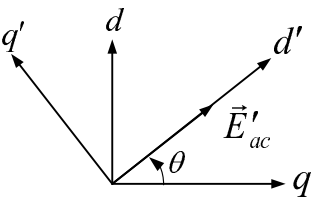

(b)

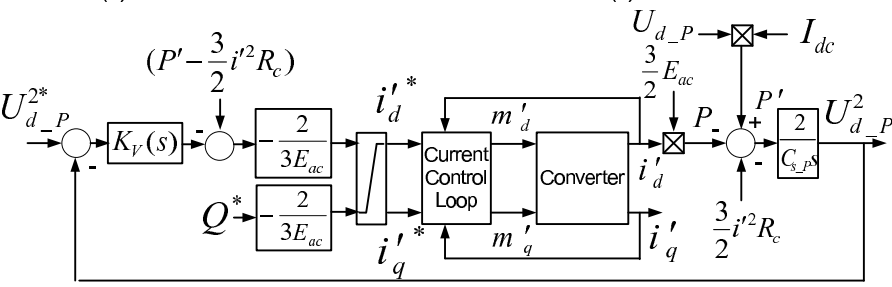

(d)

Fig. 2. (a) VSC MTDC converter model with overall control structure (for positive pole only) (b) modified reference frame for decoupled control (c) converter $P-Q$ control (d) converter $V_{D C}-Q$ control

(say, $i_{d}^{\prime}, i_{q}^{\prime}$ ) should be transformed back to $d-q$ frame while interfacing the converter with the AC network. Further details of this interfacing is shown in the Appendix. Note that, the converter could also be modeled in any reference frame irrespective of its controls. The approach followed here is widely used because it reduces the number of times one needs to change the co-ordinate systems for interfacing variables in different frames.

After transforming (2) into $q^{\prime}-d^{\prime}$ frame, the dynamics of the $\mathrm{AC}$ side of the converters is given by:

$$
\begin{gathered}
v_{d t}^{\prime}-R_{c} i_{d}^{\prime}-L_{c} \frac{d i_{d}^{\prime}}{d t}+L_{c} \omega_{e l} i_{q}^{\prime}=E_{a c} \\
v_{q t}^{\prime}-R_{c} i_{q}^{\prime}-L_{c} \frac{d i_{q}^{\prime}}{d t}-L_{c} \omega_{e l} i_{d}^{\prime}=0
\end{gathered}
$$

where, $v_{d t}^{\prime}=m_{d}^{\prime} \frac{U_{d P} P}{2}, v_{q t}^{\prime}=m_{q}^{\prime} \frac{U_{d P} P}{2}, E_{a c}=\left|\vec{E}_{a c}^{\prime}\right|$.

The DC bus dynamics at each converter end was modeled by the power balance in the capacitors. Fig. 2(d) shows the converter DC bus model as written below:

$$
P^{\prime}-P-\frac{3}{2} i^{\prime 2} R_{c}=\frac{1}{2} C_{s_{-} p} \frac{d\left(U_{d \_P}^{2}\right)}{d t}
$$

where, $P^{\prime}=U_{d_{-} P} I_{d c}, P=\frac{3}{2} E_{a c} i_{d}^{\prime}$ and $i^{\prime 2}=i_{d}^{\prime 2}+i_{q}^{\prime 2}$. Note, $I_{d c}$ is shown in Fig. 1. Similar equations are applicable for the negative pole converter as well. 


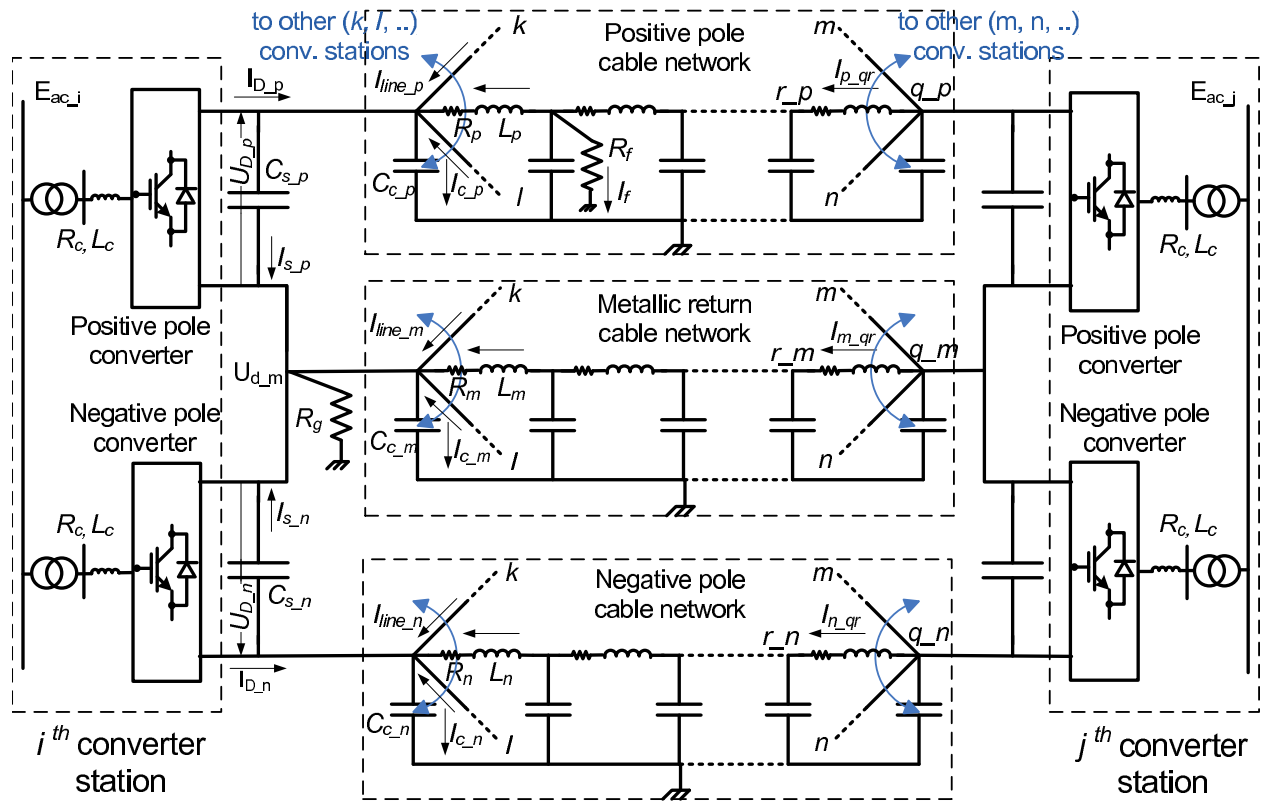

Fig. 3. DC cable network modeling with cascaded pi sections

1) Converter $P-Q$ Control: All the converter stations except one is considered to operate in $P-Q$ control mode with decoupled control strategy [10] as shown in Fig. 2(a)-(c). Note that $i_{d}^{\prime}, i_{q}^{\prime}, E_{a c}$ and $U_{d_{-} P}$ are measurable parameters, which were used as feed-forward terms with appropriate signs to achieve decoupling between $d$ and $q$ axes current control loops. The reference values of the current components were derived as:

$$
i_{d}^{* *}=\frac{2 P^{*}}{3 E_{a c}}, i_{q}^{* *}=-\frac{2 Q^{*}}{3 E_{a c}}
$$

A moderate bandwidth (BW) is adequate in tracking $i_{d}^{\prime *}$ and $i_{q}^{\prime *}$ since they are DC in nature under steady state. Thus a closed loop BW of $300 \mathrm{rad} / \mathrm{s}$ was considered while designing the controller $K_{I}(s)$ as shown in the Table I.

2) Converter $U_{d c}-Q$ Control: One of the converter stations operates in $U_{d c}-Q$ control mode maintaining constant DC bus voltage and unity power factor at the point of common coupling (PCC) as shown in Fig. 2 (d). The outer voltage control loop is slower than the inner current control loop and consists of the feed-forward terms to mitigate the measurable disturbances. A lead compensator $K_{V}(s)=0.108\left(\frac{s+231}{s+398.6}\right)$ providing a phase margin of 60 degrees at about $300 \mathrm{rad} / \mathrm{s}$ was employed to control the DC link voltage.

\section{B. DC Cable Network Modeling}

In this work a bipole MTDC grid with positive, negative and metallic return network was considered. A detailed cascaded pi-model of the cable network was used which is generic enough to handle different grounding mechanisms and unbalance as a result of outage of one or more poles. Note that in absence of either the positive/negative pole or one of the converters in a converter station, the metallic return network will carry a non-zero current. Such a scenario is termed henceforth as 'unbalance (on the DC side)'.

There are infinite number of states associated with a distributed model of the cable and therefore it is not suitable for modal analysis. Hence a cascaded pi section approximation as shown in Fig. 3 is needed and the minimum number of such sections required should be ascertained. Fig. 4 shows the comparison of the impedance spectra of the distributed model vis-a-vis the pi-section model for a $\pm 400 \mathrm{kV}, 500 \mathrm{~km}$ long cable. Obviously more pi sections will result in better

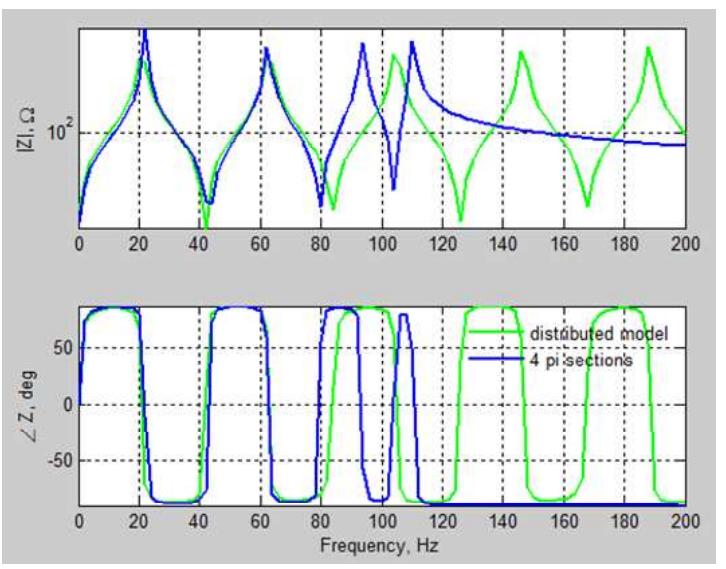

Fig. 4. Comparison of impedance spectra of a $\pm 400 \mathrm{kV}, 500 \mathrm{~km}$ long cable with distributed model and cascaded pi-section model: (a) impedance magnitude (b) impedance phase angle

approximation at the cost of complexity and computational burden. As shown in Fig. 4 a close approximation upto the AC system frequency $(60 \mathrm{~Hz})$ can be obtained with 4 cascaded pi sections which was considered adequate. The length of cable was chosen as $500 \mathrm{~km}$ considering the typical maximum subsea distances around planned Pan-European sub-sea Supergrid. The model is scalable in terms of the number of pi sections and this can be changed according to the length of the cable.

Fig. 3 shows the interconnection between the $i^{\text {th }}$ and the $j^{\text {th }}$ converter stations through the positive, negative and the metallic return cable. Each of the converter poles can be connected to the corresponding poles of any number of 
converter stations. The cable network is flexible in terms of the location of the fault and the grounding options. Here, the $i^{t h}$ converter is considered to be resistance grounded.

The mathematical model of the cable network can be described by the following set of algebraic and differential equations which are shown in a block diagram in Fig. 5.

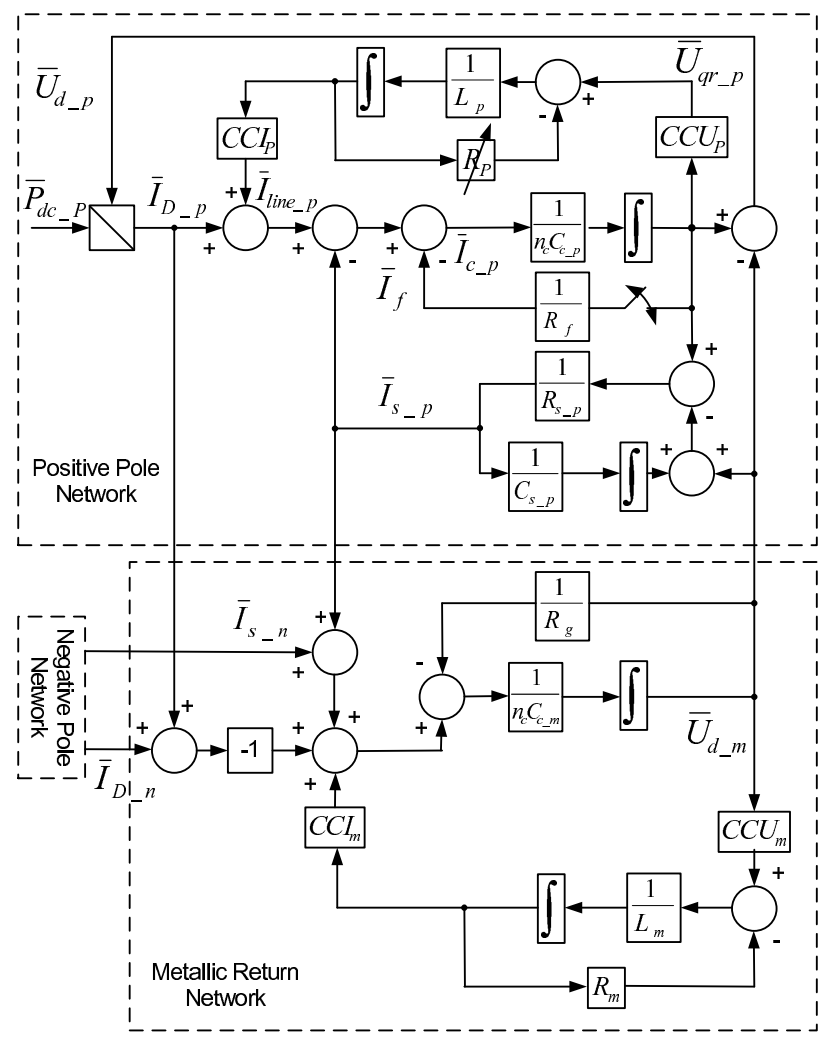

Fig. 5. Block diagram of the DC cable network dynamic model

1) Algebraic Equations: For the positive pole network, the general form of current balance at any node is given by:

$$
I_{D \_P}+I_{l i n e \_p}-I_{s \_p}-I_{c \_p}-I_{f}=0
$$

where, $I_{D_{-} P}=\frac{P_{d c_{-} p}}{U_{d \_} p}$. Depending on the connectivity and the location of the fault, some of the variables would be zeros $\left(I_{f}\right.$ is non-zero if the fault occurs at that node). For example, at the converter DC bus node all parameters are non-zeros. Any node other than that of a converter station would have zero $I_{D_{-} P}$ and $I_{s_{-} p}$. Under balanced operation the current on the metallic return circuit would be zero.

If the maximum possible number of nodes and the series $R-L$ branches are $N_{\text {nodeP }}$ and $N_{b r P}$ respectively, then

$$
\bar{I}_{\text {line_p }}=C C I_{P} \times \bar{I}_{p_{\_} q r}
$$

where, $\bar{I}_{p_{-} q r}$ is the vector of $R-L$ branch currents flowing from any general node $q \_p$ to $r \_p, \bar{I}_{\text {line_p }}$ is the total node current injection vector, shown in Fig. 3 and $C C I_{P}$ is the incidence matrix of dimension $\left[N_{\text {nodeP }} \times N_{b r P}\right]$ depending on the connectivity of different branches. The entries of $C C I_{P}$ are $C C I_{P}(i, j)=1(-1)$, if the $i^{\text {th }}$ cable enters (leaves) the $j^{\text {th }}$ node and $C C I_{P}(i, j)=0$, otherwise.

Similarly, the connectivity between the nodes is determined by the matrix $C C U_{P}$ of dimension $\left[N_{b r P} \times N_{\text {nodeP }}\right]$. It was assumed that the current in a branch will flow from the $i^{\text {th }}$ to the $j^{\text {th }}$ node if $i<j$. The elements of $C C U_{P}$ are determined as $C C U_{P}(i, j)=1$, if $i<j, C C U_{P}(i, j)=-1$, if $i>j$, all other entries are zeros where the $i^{\text {th }}$ and the $j^{\text {th }}$ node are not connected. Thus $C C U_{P}$ relates the node voltages with the voltage drop in the series $R-L$ branches by the equation

$$
\bar{U}_{q r \_p}=C C U_{P} \times \bar{U}_{q \_p}
$$

where $\bar{U}_{q \_p}$ is the node voltage vector and $\bar{U}_{q r \_p}$ is the vector of series branch voltage drops. Note that $C C I_{P}=-C C U_{P}^{T}$. Similar set of equations are applicable for the negative pole network too.

For the metallic return network (shown in Fig. 3), (7) can be modified as:

$-I_{D \_P}-I_{D \_N}+I_{\text {line_m }}+I_{s \_p}+I_{s_{-} n}-I_{c_{-} m}-\frac{U_{d \_} m}{R_{g}}-I_{f}=0$

All other above-mentioned equations are applicable for the metallic return network.

2) Differential Equations: For the positive pole network the converter station capacitor dynamics is given by:

$$
U_{d \_p}=\frac{1}{C_{s \_p}} \int I_{s \_p} d t+I_{s \_p} R_{s \_p}
$$

where, $R_{s_{-} p}$ is the effective series resistance ESR (not shown explicitly in Fig. 3). For any cable node $q \_p$ we can write:

$$
\frac{1}{n_{c} C_{c \_p}} \int I_{c q \_p} d t=U_{q \_p}
$$

Here, $n_{c}$ depends on the node location, e.g. at any cable node other than the converter node, $n_{c}=2$. Note that the parameter $C_{c \_p}(14 \mu \mathrm{F}$ as mentioned in Table I) is the capacitance at each end of a pi-section in the cable model. Therefore it is half the total capacitance in each pi section. The series $R-L$ branch dynamics can be described by:

$$
L_{p} \frac{d I_{p \_q r}}{d t}+R_{p} I_{p \_q r}=U_{q \_p}-U_{r \_p}=U_{q r \_p}
$$

The negative pole and metallic return network dynamics can also be represented by similar equations.

\section{Combined AC-MTDC Grid Modeling}

The model of the combined AC-MTDC grid is shown in Fig. 6. In the multi-machine $\mathrm{AC}$ system the generators, excitation systems, loads and other dynamic components were modeled by their respective differential and algebraic equations (DAEs). The AC network was represented algebraically by the bus admittance matrix $Y_{\text {bus }}$. A set of current balance equations including the current injection from the MTDC grid $\vec{I}_{M T D C}$ were solved to find the AC network bus voltages.

The voltages at the PCC of the MTDC grid $\left(\vec{E}_{a c}\right)$ were locked with the $d$-axis of the synchronously rotating $q^{\prime}-d^{\prime}$ reference frame (Fig. 2(b)). The AC currents injected by the positive and negative pole converters $\vec{I}_{a c \_p / n}^{\prime}=i_{d \_p / n}^{\prime}+$ $j i_{q \_p / n}^{\prime}$ were calculated using the converter and controller model shown in Fig. 2(a). The DC side power $\left(P_{d c_{-} p / n}\right)$ of the converters was derived from the PCC real power after accounting for the losses. $P_{d c \_p / n}$ was further used as input to 


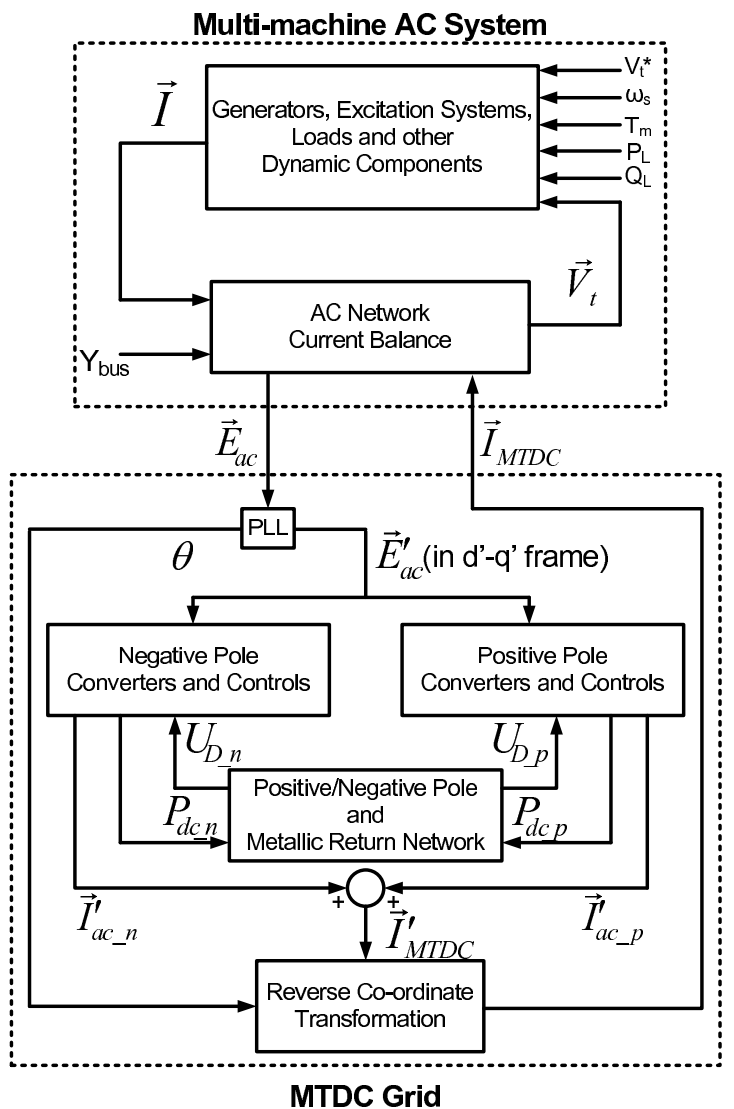

Fig. 6. Block diagram of combined AC-MTDC grid model

the DC cable model (Fig. 5) to obtain the DC link voltages. The converter AC side current was transformed into the AC system common $d-q$ reference to solve the current balance equations.

\section{Fault and Converter Outage Simulation}

Fault and cable outage were simulated by lowering the resistance at the fault point followed by increase in breaker resistance. As shown in Fig. 5 the fault resistance $R_{f}$ was inserted by means of a switching function depending on the time and the duration of the fault. Note that the entire formulation can be vectorized with $R_{f}$ inserted selectively corresponding to the faulted node. During fault, the value of $\frac{1}{R_{f}}$ was increased from zero to 100 . Converter blocking and uncontrolled rectification through anti-parallel diodes during DC cable faults were included. The faulted cable was isolated by opening the DC breaker at either end, which is emulated by inserting a high breaker resistance of $10^{6} \Omega$ [13].

Converter outage was simulated by opening both the DC side and the $\mathrm{AC}$ side breakers at the respective converter pole. However, the DC cable connections to the switchyard of the affected converter were retained.

The proposed model is generic and modular enough to handle any:

- configuration of bipolar MTDC grid converter stations.

- grounding options along with metallic return network.

- number of pi section approximation of DC cable model.
- type and location of fault on the DC side.

- cable outage or converter outage leading to unbalanced (on DC side) operation.

\section{Validation Against Detailed Switched Model IN EMTDC/PSCAD}

The averaged model of the following study network in Matlab/SIMULINK was validated against a detailed switched model in EMTDC/PSCAD including the switching action of the converters. Sinusoidal PWM technique was considered for switching pulse generation at a frequency of $1980 \mathrm{~Hz}(33 \times 60$ $\mathrm{Hz})$.

\section{A. Study Network}

The study network consisting of four bipole converter stations connected with $500 \mathrm{~km}$ cables is shown in Fig. 7. Two

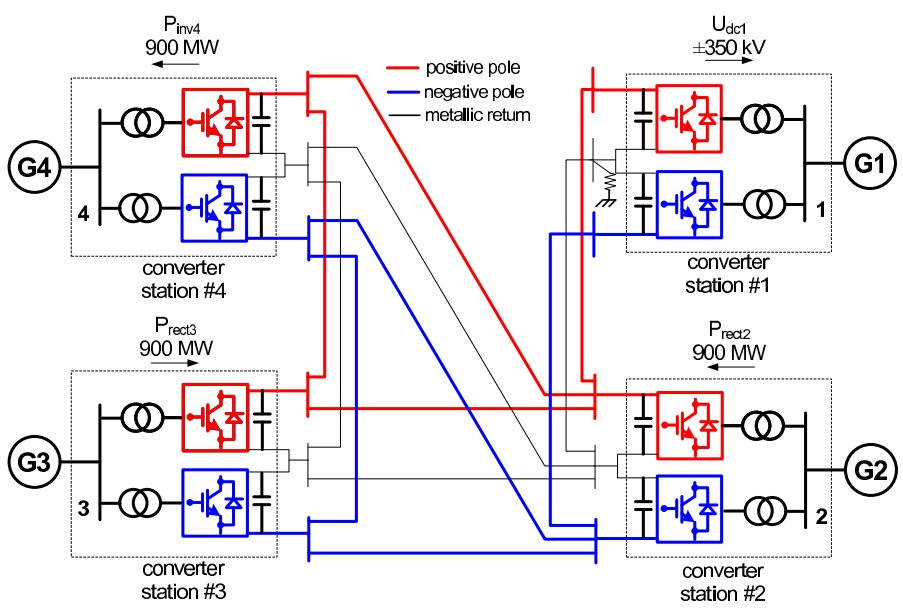

Fig. 7. Bipole MTDC grid with four converter stations

converter stations (\#2 and \#3) are considered to be acting as rectifiers and the others (\#1 and \#4) as inverters under nominal condition. Three converter stations are in P-Q control mode each maintaining $900 \mathrm{MW}$ real power at unity power-factor (upf) at the PCC buses \#2, \#3 and \#4 as shown in Fig. 7. Real power injected into the $\mathrm{AC}$ system is considered to be positive and vice versa for the rest of the paper. Converter station \#1 operates in $V_{d c}-Q$ control mode and keeps the DC link voltage at $\pm 350 \mathrm{kV}$ with upf at the PCC. The metallic return is grounded with a $0.5 \Omega$ resistance at the converter station \#1 while the other stations are left ungrounded.

The parameters of the above study network are shown in the Table I.

TABLE I

MTDC GRID PARAMETERS FROM FIGS 2, 3

\begin{tabular}{|c|c||c|c|}
\hline Parameters & Values & Parameters & Values \\
\hline \hline$R_{c}$ & $0.07 \Omega$ & $C_{s_{-} p} / C_{s_{-} n}$ & $0.4 \mathrm{mF}$ \\
\hline$L_{c}$ & $40.0 \mathrm{mH}$ & $R_{s_{-} p} / R_{s_{-} n}$ & $1.0 \mu \Omega$ \\
\hline$R_{g}$ & $0.5 \Omega$ & $R_{p} / R_{n} / R_{m}$ & $1.5 \Omega$ \\
\hline$L_{m}$ & $0.30 \mathrm{H}$ & $L_{p} / L_{n}$ & $0.30 \mathrm{H}$ \\
\hline$C_{c_{-} m}$ & $40.0 \mu \mathrm{F}$ & $C_{c_{-} p} / C_{c_{\_} n}$ & $14.00 \mu \mathrm{F}$ \\
\hline$R_{f}$ & $0.01 \Omega$ & $K_{I}(s)$ & $300\left(\frac{R_{c}+s L_{c}}{s}\right)$ \\
\hline
\end{tabular}

The surrounding AC system was modeled by an ideal 400 $\mathrm{kV}$ voltage source behind a series impedance $(0.3+j 4.0 \Omega)$. 

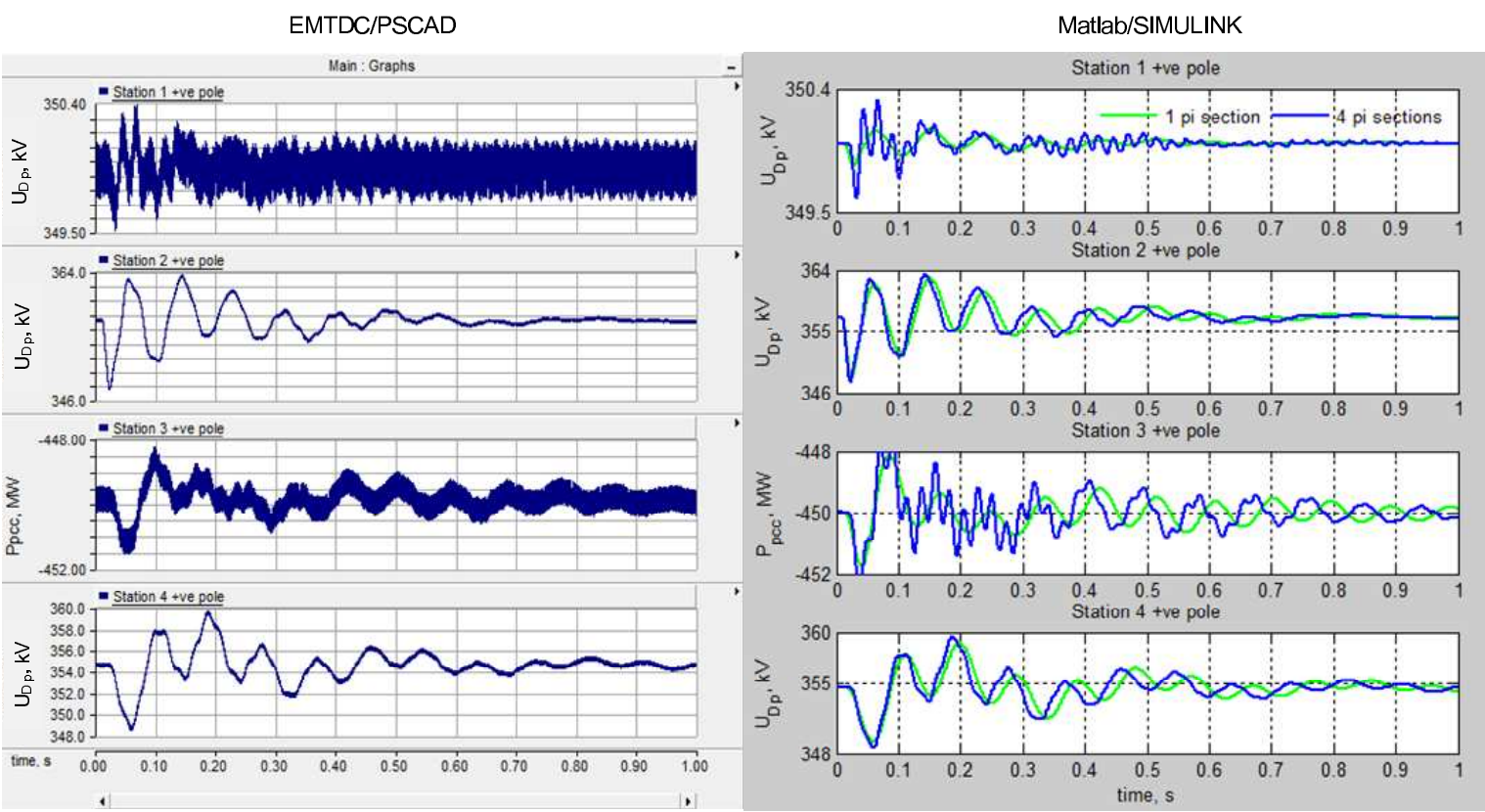

Fig. 8. Validation of the averaged model in Matlab/SIMULINK against detailed switched model in EMTDC/PSCAD. A pulse change to the real power reference of both the converters in converter station \#2 is applied
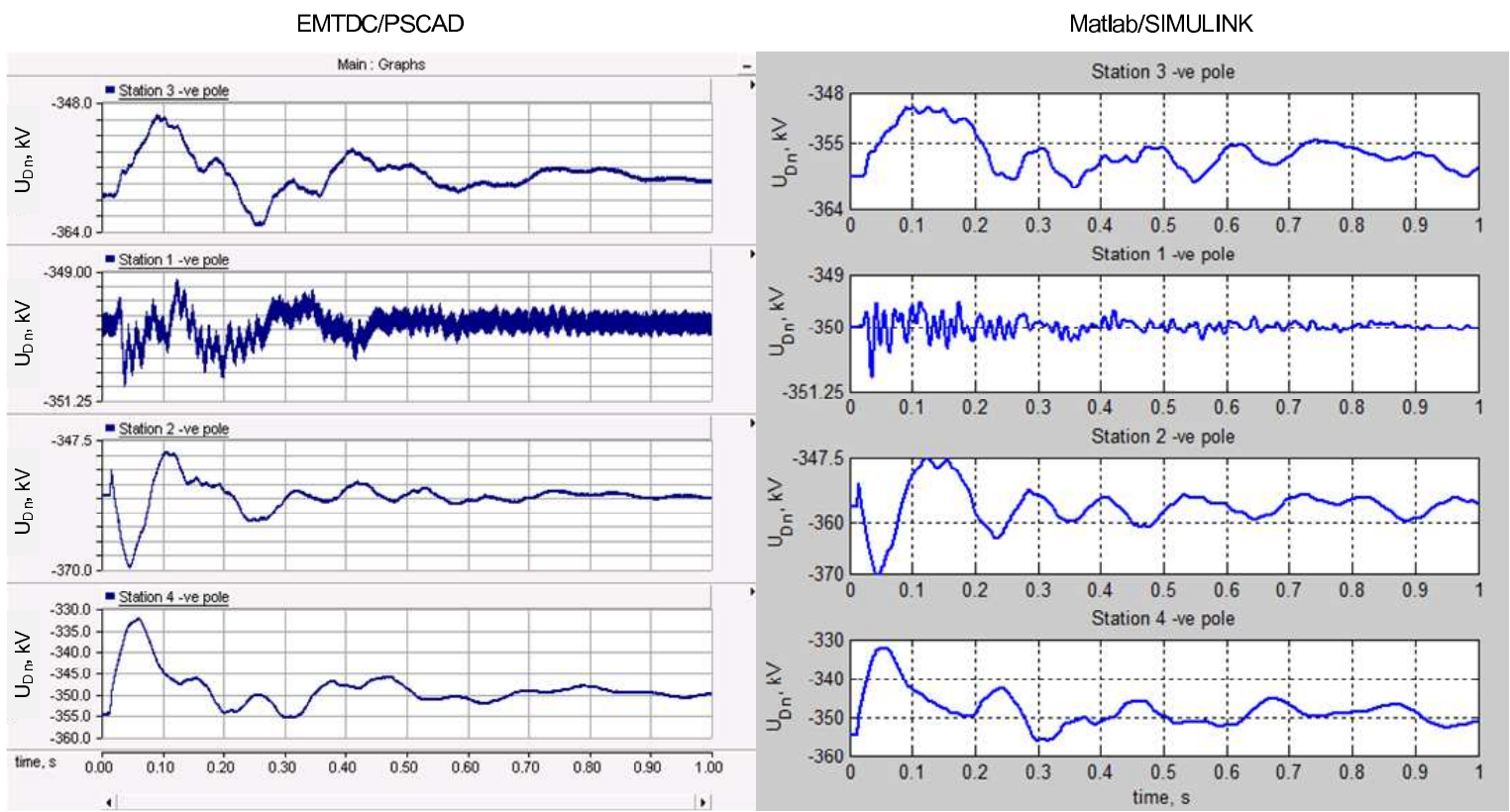

Fig. 9. Comparison of the dynamic behaviour of the averaged model in Matlab/SIMULINK against detailed switched model in EMTDC/PSCAD. A cable fault at the mid-point of the negative pole connecting converter stations \#2 and \#4 followed by its outage is simulated

The steady state operating condition was determined by solving the AC-DC load-flow equations [14], [15].

\section{B. Validation for Small Disturbances}

As discussed in Section II-B, the approximation of the distributed cable model by 4 pi-sections can be considered adequate for $\pm 400 \mathrm{kV}, 500 \mathrm{~km}$ cable, as seen from the impedance spectra (Fig. 4). Therefore, 4 pi sections were used to model each DC cable in EMTDC/PSCAD.

Fig. 8 shows the dynamic behavior of the system in response to a pulse change applied to $P_{r e f}$ of both the converters in converter station \#2. Due to symmetry, only the positive pole variables are shown here. A close look at the responses show very good match between the detailed switched model in EMTDC/PSCAD and the averaged model in Matlab/SIMULINK. The former was run with a fixed step size of $0.5 \mu \mathrm{s}$ while the latter was run with a variable step solver. The dynamic response observable in the EMTDC/PSCAD are clearly captured in the Matlab/SIMULINK model except for the switching ripples.

Note that the DC link voltage of converter station \#1 is tightly held at $\pm 350 \mathrm{kV}$ (check the tight scale of top left subplot) - hence visually appearing to have larger ripple content than the others. The resulting DC link voltages at 
stations \#2 and \#3 are slightly higher $( \pm 355 \mathrm{kV})$ due to the direction of power flow in the DC network. The subplots on the right column of Fig. 8 also compares the performance of the averaged model in Matlab/SIMULINK when the cables are approximated by only 1 pi section instead of 4 . A single pi section could not capture certain high frequency modes and showed substantial phase-shift in the response of the low frequency modes thus justifying the use of 4 pi sections for this study.

\section{Validation for Large (DC cable faults) Disturbances}

In the previous subsection the Matlab/SIMULINK model was validated against the EMTDC/PSCAD for small (pulse) disturbances. In this subsection large disturbances in the form of DC side faults is considered. The dynamic response of the system following a line to ground fault at the mid-point of the negative pole cable connecting converter stations \#2 and \#4 followed by the outage of the faulted cable is shown in Fig. 9. The DC bus voltages of the converter stations show large peak deviations from the pre-fault steady state values except for converter \#1.

It can be seen that the response of the averaged model is reasonably similar to that of the switched model - although not as close as that in the previous case study with a pulse disturbance. This is possibly due to the occurrence of transients in presence of cable capacitance, and other probable factors including different types of solvers and simulation step size used in the two platforms.

Successful validation of the Matlab/SIMULINK model against the EMTDC/PSCAD gives the confidence for adopting it in modal analysis.

\section{MODAl ANALYSIS}

The MTDC grid modeled by the differential-algebraic equations (DAEs) in (3)-(13) were linearized around a nominal condition and expressed in state-space form as:

$$
\Delta \dot{x}=A \Delta x
$$

where, $\Delta x$ and $A$ are the state-vector and state-matrix, respectively. The order of the state matrix for the study network considered was 186 . The right $\left(\phi_{i}\right)$ and left $\left(\psi_{i}\right)$ eigen vectors corresponding to the eigenvalues $\lambda_{i}, i=1,2, \ldots, n$ satisfy:

$$
A \phi_{i}=\lambda_{i} \phi_{i}, \psi_{i} A=\lambda_{i} \psi_{i}
$$

The $k^{\text {th }}$ element of the right eigenvector $\phi_{i}$ measures the activity of the state variable $x_{k}$ in the $i^{\text {th }}$ mode while that of the left eigenvector $\psi_{i}$ weighs the contribution of this activity to the $i^{t h}$ mode [16].

To get around the scaling problem often the above measures are combined to form the participation matrix, $P$ whose elements $p_{k i}=\phi_{k i} \psi_{i k}$ are termed as the participation factor. It is a measure of the relative participation of the $k^{t h}$ state variable in the $i^{t h}$ mode and vice versa [16]. Note that $p_{k i}$ is dimensionless and $\sum_{i=1}^{n} p_{k i}=\sum_{k=1}^{n} p_{k i}=1$.

Modal participation analysis was done to figure out the nature and the root cause of the dynamic response of the
MTDC grid. It can be seen from the pole map of Fig. 10 (upper subplot) that the fastest modes are associated with the AC network (modeled by transformer and phase reactor impedance) states and the participation of the DC network and the converter controller states increase as we move towards right on the s-plane. The lower subplot shows a zoomed view of the critical poles. Most of these are associated with the DC network except one pole pair which has high participation from the current controllers of the converters.

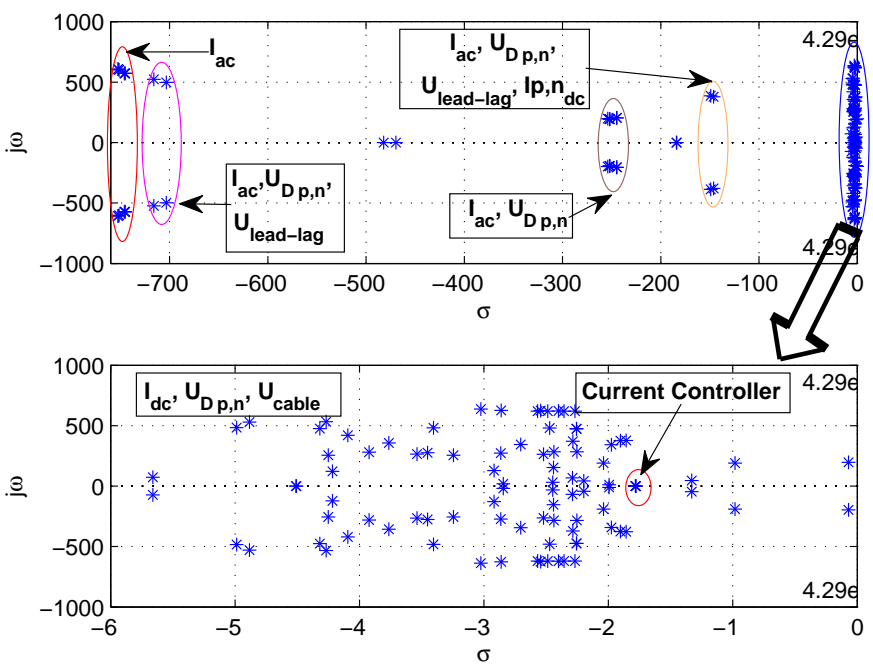

Fig. 10. Clustering of system poles based on participation factors

\section{Case Study with MTdC Grid Connected to A Multi-MaChine AC System}

In Section III the averaged model of the MTDC grid was validated against the detailed switched model both for small and to a reasonable extent, large disturbances. To study possible interactions, the same MTDC grid as above (in Fig. 7) was connected to AC systems with six generators as shown in Fig. 11. Each generator $(G 1-G 6)$ was represented by a sub-transient model. The active component of the loads were modeled as constant current and the reactive component as constant impedance. The details of the AC system can be found in [16]. Other than the differential equations involving the converter transformers and phase reactors, the rest of the AC circuit (generator transformers, and transmission lines) was represented algebraically. The standard DAE model of the multi-machine AC system [11], [16] in the current injection framework was integrated with the dynamics of the converter transformers and phase reactors (refer to (3), (4)) with proper adjustment of the $d-q$ reference frame as described in Section II-A.

Under the nominal condition, each of $G 1, G 2$ and $G 4$ generates $700 \mathrm{MW}, G 3, G 5$ and $G 6$ are left as slack. The tie-line transfer through the AC line connecting buses \#9 and \#10 is $200 \mathrm{MW}$ while converter stations \#2, \#3 and \#4 operate in $P-Q$ mode to maintain $900 \mathrm{MW}, 300 \mathrm{MW}$ and $900 \mathrm{MW}$ respectively at upf at the PCC as shown in Fig. 11. Converter 


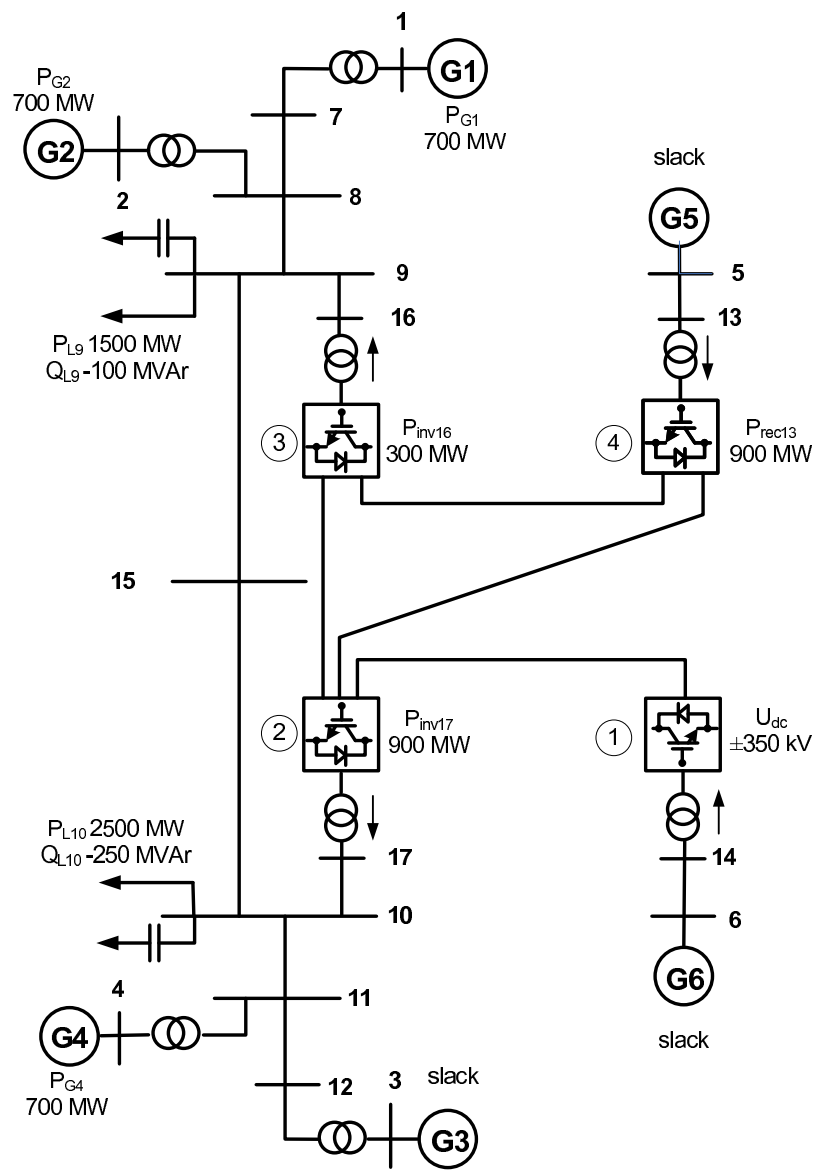

Fig. 11. Bipole MTDC grid (single line diagram) connected to a multimachine AC system

station \#1 works in $V_{d c}-Q$ mode and keeps the DC link voltage constant at $\pm 350 \mathrm{kV}$.

\section{A. Modal Analysis}

The modal participation factor analysis was done to associate the oscillatory modes to different state variables of the combined AC-MTDC grid. Fig. 12 shows the pole map of the $246^{\text {th }}$ order test system. As expected, in addition to the modes associated with the MTDC grid shown in Section IV, the participation of generator modes is more prominent as we move from left to right of the s-plane as shown in Fig. 12. There exists a poorly damped inter-area mode of $0.55 \mathrm{~Hz}$ frequency and $0.3 \%$ damping where the states of generators, $G 1-G 4$ have the strongest participation as seen from the lower right subplot of Fig. 12.

\section{B. AC side fault}

Non-linear simulations in Matlab/SIMULINK involving both AC and DC side faults were done. Fig. 13 shows the dynamic behavior of the system following a three-phase selfclearing fault for about 5 cycles near bus $\# 15$ at $t=0.01 \mathrm{~s}$. In accordance with the modal analysis, the angular separation between $G 1$ and $G 3$ shows the presence of the poorly damped but stable inter-area mode (Fig. 13(a)). On the other hand it can be seen from Figs 13(b) and (c) that the positive pole

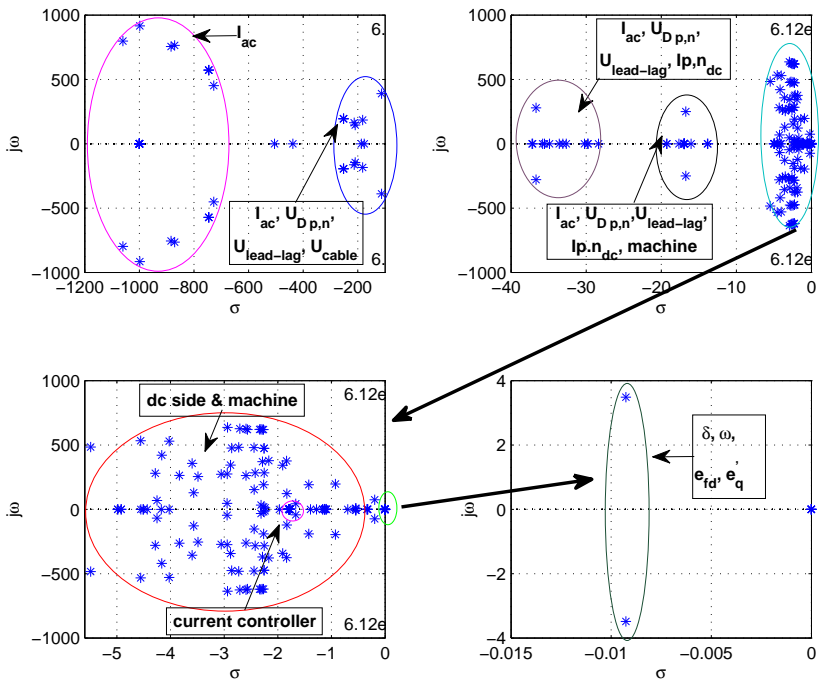

Fig. 12. Clustering of system poles based on participation factor analysis for the MTDC grid connected to a multi-machine AC system shown in Fig. 11

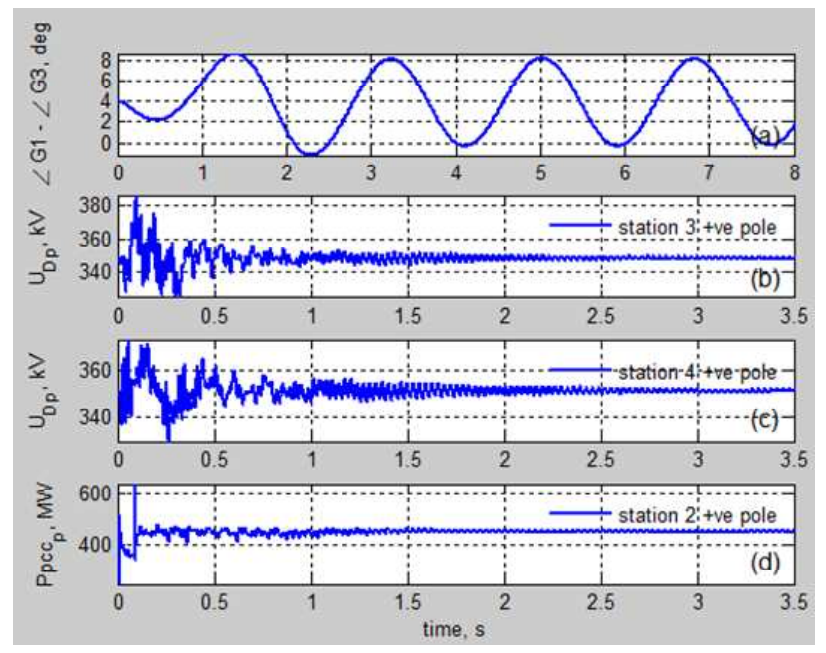

Fig. 13. Dynamic performance of the combined AC-MTDC system (shown in Fig. 11) following a three-phase self-clearing fault at bus \#15 for $80 \mathrm{~ms}$ starting at $\mathrm{t}=0.01 \mathrm{~s}$

DC link voltages of the stations \#3 and \#4 include higher frequency oscillatory modes. Careful observation of converter station \#3 DC link voltage reveals the presence of an $11 \mathrm{~Hz}$ mode immediately after the fault followed by appearance of another mode with approximately $30 \mathrm{~Hz}$ frequency. These can primarily be attributed to the eigenvalues: $-0.1948 \pm j 73.6592$ and $-0.9259 \pm j 196.7692$ having very high participation from the DC network states as shown in Fig. 12. After the transient all the parameters settle back to their pre-fault values - e.g. converter station \#2 positive pole maintains around $450 \mathrm{MW}$ (half of $900 \mathrm{MW}$ ) flow at bus \#17 as shown in Fig. 13(d).

\section{DC side fault}

Next, a DC cable fault was considered at the mid point of the negative pole cable connecting the converter stations $\# 2$ and \#4. The fault was created at $t=0.01 \mathrm{~s}$ and cleared 
by opening the faulted cable within $5.0 \mathrm{~ms}$. It can be seen

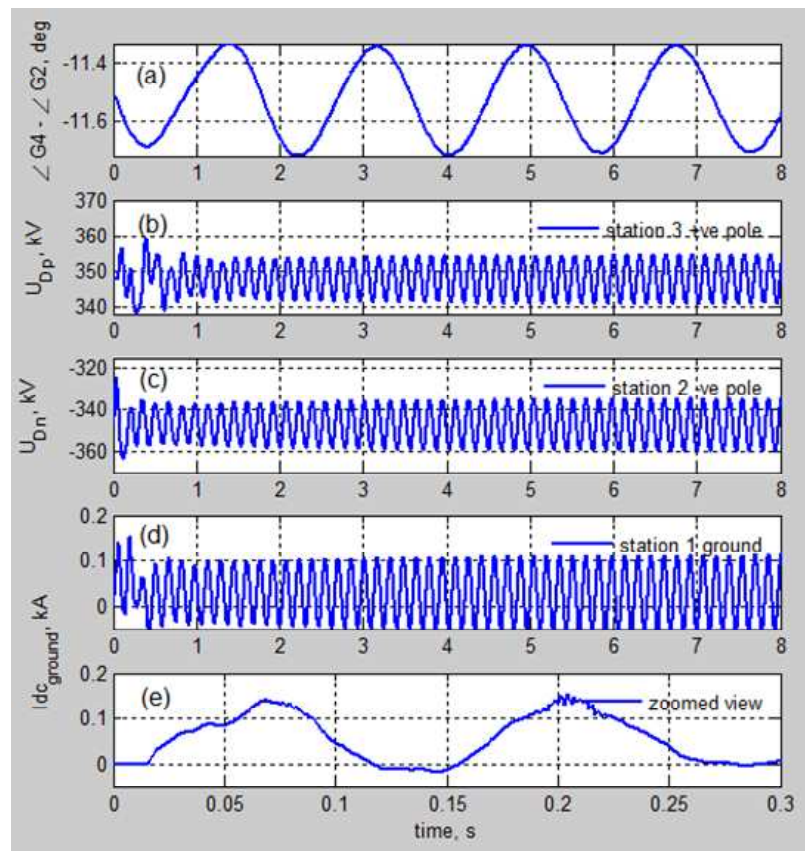

Fig. 14. Dynamic performance of the combined AC-MTDC system (shown in Fig. 11) following a cable fault at the mid-point of the negative pole connecting converter station \#2 and \#4. The fault occurs at $\mathrm{t}=0.01 \mathrm{~s}$ and is cleared within $5 \mathrm{~ms}$ by isolating the faulted cable

from Fig. 14(a) that the poorly damped (but stable) interarea mode is observable in the angular difference between $G 4$ and $G 2$. The DC link voltage of the positive pole at converter station \#3, shown in Fig. 14(b), oscillates about its pre-fault value $(348 \mathrm{kV})$ similar to the other $\mathrm{DC}$ side variables (Figs 14(c),(d)). The converter station \#2 negative pole DC link voltage dips due to its vicinity to the fault on the cable connecting the converter stations \#2 and \#4 as shown in Fig. 14(c).

Also worth noting is the oscillations in the ground current at the converter station \#1 after the faulty negative pole cable is isolated (Fig. 14(d)). A zoomed view of this current in Fig. 14(e) highlights that the zero pre-fault current becomes non zero in the post-fault condition due to unbalance (on DC side).

From the variations of several DC side quantities in Fig. 14(b),(c),(d), it is clear that the system approaches instability. This however, is not apparent from the angular difference between the generators $G_{4}$ and $G_{2}$ on the AC side shown in Fig. 14(a). It is to be noted that for a DC cable fault the oscillations between $G_{4}$ and $G_{2}$ on the AC side is much smaller than that in the case of AC side fault as shown in Fig. 13(a). Modal analysis was used to identify the critical modes associated with the AC and DC sides as shown in Table II. It can be seen that outage of a DC cable has virtually no impact on the inter-area $(0.55 \mathrm{~Hz})$ mode which is reflected in similar responses of the angular differences between the generators as shown in Figs 13(a) and 14(a). However, the 7.0 $\mathrm{Hz}$ mode with high participation from the DC network states (refer to Fig. 12) becomes unstable which is manifested in the responses in Fig. 14(b),(c),(d).
TABLE II

CRITICAL Modes of THE MTDC GRID CONNECTED TO A MULTI-MACHINE AC SYSTEM

\begin{tabular}{|c|c|c|}
\hline Pre-fault & Post-fault & Mode Type \\
\hline \hline$-0.0093 \pm \mathrm{j} 3.4864$ & $-0.0093 \pm \mathrm{j} 3.4864$ & Inter-Area \\
\hline$-1.6650 \pm \mathrm{j} 42.3202$ & $0.1975 \pm \mathrm{j} 40.2715$ & DC Network \\
\hline
\end{tabular}

From the above results it can be inferred that an averaged converter model along with the DC cable network should be taken into account while analyzing the stability and the dynamics of combined AC-MTDC systems.

\section{Converter Outage}

The outage of the negative pole converter of the converter station \#3 (inverter) was considered at $\mathrm{t}=0.5 \mathrm{~s}$ by opening the AC side breaker. It can be seen from Fig. 15(b) that the power flow at the PCC of the negative pole of station \#3 becomes zero while those of the stations \#2 and \#4 remain constant as they are in $P-Q$ control. The negative pole

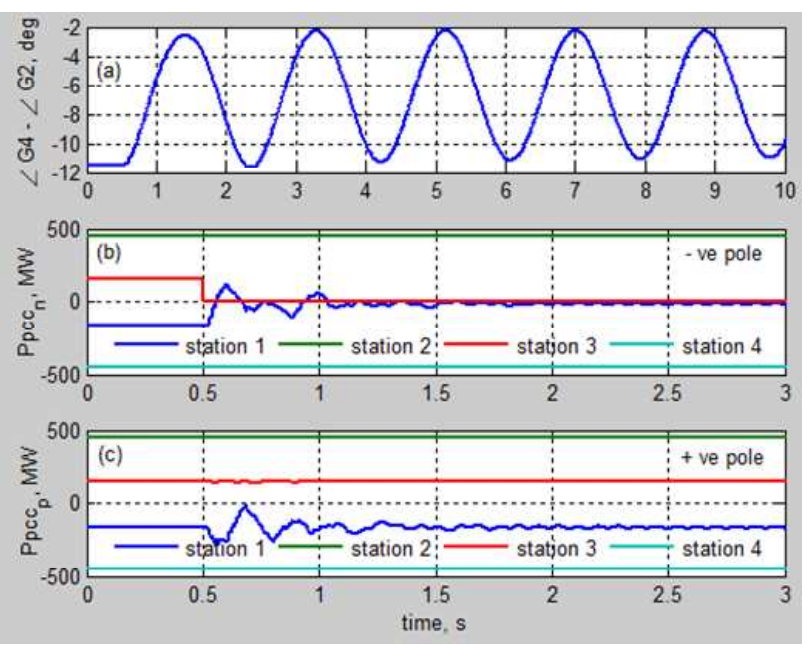

Fig. 15. Dynamic performance of the combined AC-MTDC grid (shown in Fig. 11) following the outage of the negative pole converter at the converter station \#3

converter of the station \#1 (rectifier) operating in $U_{d c}-Q$ mode reduces its power by about $150 \mathrm{MW}$ (lost due to outage of converter in station \#3) while the positive pole converter powers, shown in Fig. 15(c), remain at their respective prefault values. The angular difference between the generators $G 4$ and $G 2$ in Fig. 15(a) shows stable but poorly damped oscillations around a reduced average (absolute) value due to less power flow through the AC tie-line connecting buses 9 and 10.

Fig. 16 shows the dynamic behavior of the converter DC link voltages and the metallic return network current. The unbalance in the DC side of the converter stations \#1 and \#3 results in non-zero metallic return current in those converters as shown in Fig. 16(c). Although the negative pole converter in station \#3 is absent, the switchyard in the DC side remains connected with the DC cable network and the corresponding converter station voltage is shown in Fig. 16 (a). High frequency oscillations are observed on the DC link 

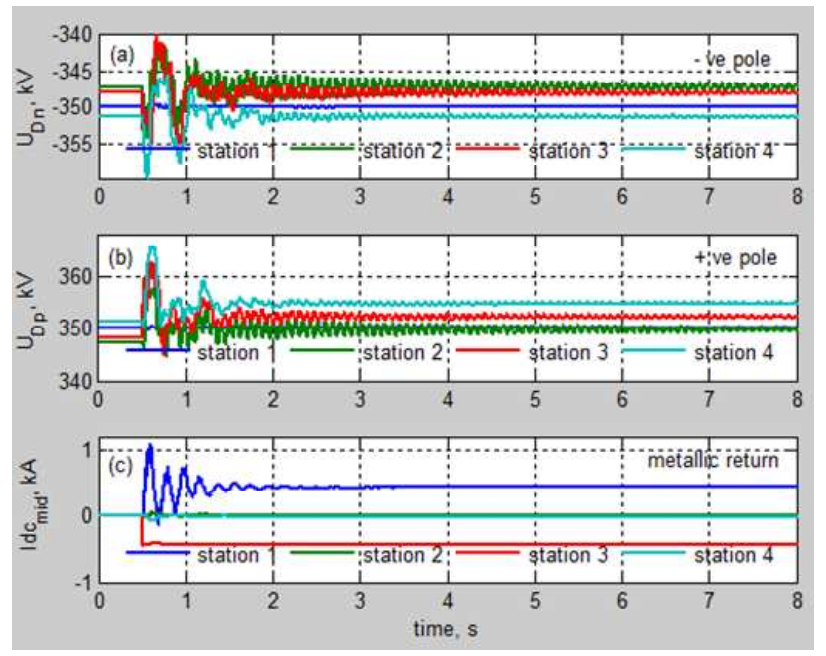

Fig. 16. Dynamic performance of the converter DC link voltages and the metallic return network current in the combined AC-MTDC grid (shown in Fig. 11) following the outage of the negative pole converter at the converter station \#3

voltages except at the converter station \#1 - where the voltage is tightly regulated at $\pm 350 \mathrm{kV}$.

\section{CONCLUSION}

Modeling framework for a general asymmetric bipole MTDC grid comprising positive and negative pole converters and DC cable network with positive, negative and metallic return circuit has been developed. Compatibility with the standard multi-machine AC system model was ensured for modal analysis and transient simulation of combined ACMTDC grids. Averaged model in Matlab/SIMULINK was validated against the detailed switched model in EMTDC/PSCAD for both small and large disturbances (e.g. DC cable faults). Interaction between a multi-machine $\mathrm{AC}$ system and an MTDC grid following faults on both AC and DC sides and outage of converters shows that instability in certain cases could only be associated with the DC side state variables. An averaged model of the converter along with the DC cable network is therefore, essential to analyze the stability and dynamics of combined AC-MTDC grids. The present study provides the platform for our ongoing research on possible interactions amongst the primary controls (e.g. autonomous power sharing etc.) of MTDC grids and the AC systems.

\section{APPENDIX}

\section{A. Co-ordinate Transformation}

The transformation of any space-phasor $\vec{\Gamma}=\Gamma_{q}+j \Gamma_{d}$ in the AC system reference frame $(d-q)$ to the converter reference frame $\left(q^{\prime}-d^{\prime}\right)$ as shown in Fig. 17, involves the following steps.

$$
\begin{gathered}
\Gamma_{d}=|\vec{\Gamma}| \sin \theta, \Gamma_{q}=|\vec{\Gamma}| \cos \theta \\
{\left[\begin{array}{c}
\Gamma_{d}^{\prime} \\
\Gamma_{q}^{\prime}
\end{array}\right]=\left[\begin{array}{cc}
\sin \phi & \cos \phi \\
\cos \phi & -\sin \phi
\end{array}\right]\left[\begin{array}{c}
\Gamma_{d} \\
\Gamma_{q}
\end{array}\right]} \\
\vec{\Gamma}^{\prime}=\Gamma_{d}^{\prime}+j \Gamma_{q}^{\prime}
\end{gathered}
$$

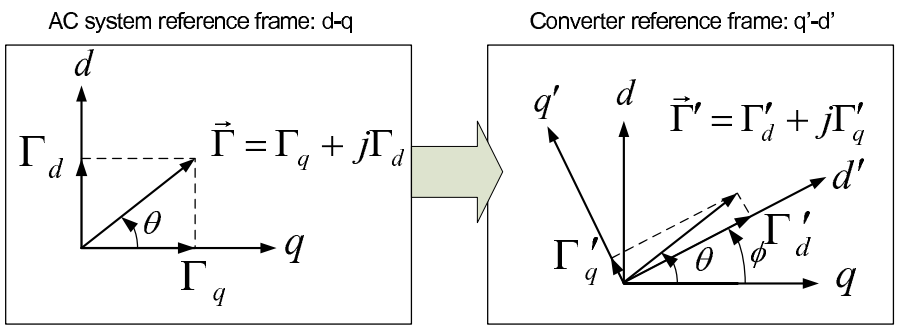

Fig. 17. Co-ordinate transformation of a space-phasor $\vec{\Gamma}$ in AC system reference frame $(d-q)$ to converter reference frame $\left(q^{\prime}-d^{\prime}\right)$

For example, when the PLL locks the $d^{\prime}$-axis with the spacephasor $\vec{\Gamma}=\vec{E}_{a c}$, the angle $\phi$ becomes equal to $\theta$. This results in $\Gamma_{q}^{\prime}=0$. Reverse transformation from $q^{\prime}-d^{\prime}$ to $d-q$ frame also follows similar steps.

\section{REFERENCES}

[1] J. Blau, "Europe plans a north sea grid," IEEE Spectrum, vol. 47, no. 3, pp. 12-13, 2010.

[2] S. Lefebvre, W. K. Wong, J. Reeve, M. Baker, and D. Chapman, "Considerations for modeling MTDC systems in transient stability programs," IEEE Transactions on Power Delivery, vol. 6, no. 1, pp. 397-404, 1991.

[3] S. Lefebvre, W. K. Wong, J. Reeve, J. M. Gagnon, and B. K. Johnson, "Experience with modeling MTDC systems in transient stability programs," IEEE Transactions on Power Delivery, vol. 6, no. 1, pp. 405-413, 1991.

[4] S. Cole, J. Beerten, and R. Belmans, "Generalized dynamic VSC MTDC model for power system stability studies," IEEE Transactions on Power Systems, vol. 25, no. 3, pp. 1655-1662, 2010.

[5] C. Zheng, X. Zhou, and L. Ruomei, "Dynamic modeling and transient simulation for VSC based HVDC in multi-machine system," in International Conference on Power System Technology, 2006. PowerCon 2006, 2006, pp. 1-7.

[6] C. Hairong, W. Chao, Z. Fan, and P. Wulue, "Control strategy research of VSC based multiterminal HVDC system," in IEEE PES Power Systems Conference and Exposition, 2006. PSCE '06. 2006.

[7] X. Lie, Y. Liangzhong, and M. Bazargan, "Dc grid management of a multi-terminal hvdc transmission system for large offshore wind farms," in International Conference on Sustainable Power Generation and Supply, 2009. SUPERGEN '09, 2009, pp. 1-7.

[8] L. Fei, M. Zhiwen, Y. Xiaojie, and Z. Trillion, "The grid connected converter control of multi-terminal DC system for wind farms," in Proceedings of the Eighth International Conference on Electrical Machines and Systems, 2005. ICEMS 2005, vol. 2, 2005, pp. 1021-1023 Vol. 2.

[9] T. Lianxiang and O. Boon-Teck, "Locating and isolating DC faults in multi-terminal DC systems," IEEE Transactions on Power Delivery, vol. 22, no. 3, pp. 1877-1884, 2007.

[10] C. Schauder and H. Mehta, "Vector analysis and control of advanced static var compensators," IEE Proceedings on Generation, Transmission and Distribution, vol. 140, no. 4, pp. 299-306, 1993.

[11] P. W. Sauer and M. A. Pai, Power system dynamics and stability. Upper Saddle River, N.J.: Prentice Hall, 1998.

[12] S. R. Sanders, J. M. Noworolski, X. Z. Liu, and G. C. Verghese, "Generalized averaging method for power conversion circuits," IEEE Transactions on Power Electronics, vol. 6, no. 2, pp. 251-259, 1991.

[13] PSCAD/EMTDC v. 4.2.1, Manitoba HVDC Research Centre, Winnipeg, MB, Canada.

[14] J. Arrillaga and B. D. Smith, AC-DC power system analysis. Stevenage: Institution of Electrical Engineers, 1998.

[15] J. Arrillaga, Y. H. Liu, and N. R. Watson, Flexible power transmission: the HVDC options. John Wiley, 2007.

[16] P. Kundur, Power system stability and control, ser. The EPRI power system engineering series. New York; London: McGraw-Hill, 1994.

Nilanjan Ray Chaudhuri (S'08-M'09) received his PhD from Imperial College London in 2011. He was with GE, John F. Welch Technology Center, 
Bangalore, India, till 2007. He was a research scholar at the University of Western Ontario (UWO), London, ON, Canada. His research interests include power system dynamics and control, application of power electronics in power systems, online system identification, FACTS, HVDC and renewable energy systems.

Rajat Majumder (S'03M'06) received the Ph.D. degree in electrical power systems from Imperial College London, London, U.K., in January 2006. He is with ABB Corporate Research, Raleigh, NC, USA, working on ABBs future developments in FACTS and HVDC technologies. He has also worked as a Lecturer in Power and Energy Systems at the University of Queensland, Brisbane, Australia, between 2006-2007. His research interest is power systems dynamics and control.

Balarko Chaudhuri (S'02-M'06) received his PhD from Imperial College London in 2005. He worked with General Electric Global Research for a year before coming back to Imperial College as a post-doctoral research associate in 2006. He is presently a lecturer in the department of Electrical and Electronic Engineering at Imperial College London. His research interests are in the areas of power system dynamics and stability, FACTS/HVDC, robust control and renewable energy.

Jiuping Pan (SM'04) received B.S. and M.S. in electric power engineering from Shandong University, China and Ph.D. in electrical engineering from Virginia Tech, USA. He is currently a Principal R\&D Engineer with ABB Corporate Research (US Center). His expertise and research interests include power system modeling and analysis, HVDC transmission, power system planning and energy market, integration of renewable energy sources. 